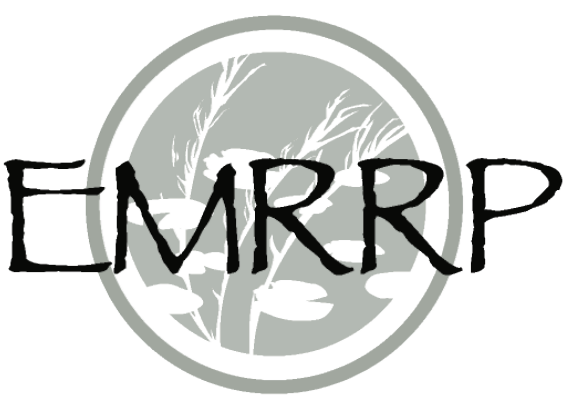

\title{
Application and Validation Study of the HEC-RAS-RVSM Model to the Sacramento River
}

by Zhonglong Zhang, Billy Johnson, Junna Wang, and Blair Greimann

PURPOSE: The riparian vegetation simulation module (RVSM) was developed and integrated into the Hydrologic Engineering Center-River Analysis System (HEC-RAS) to predict spatially explicit seed dispersal, seedling establishment, plant growth, and mortality in response to riverine hydraulic conditions. The HEC-RAS-RVSM model is capable of predicting dynamic hydraulic roughness and simulating the interactions of flow and riparian vegetation on floodplains. In this study, the HEC-RAS-RVSM was applied to the Sacramento River reach to evaluate its modeling capabilities with regard to vegetation changes and interactions between flow and riparian vegetation dynamics. The purpose of this Ecosystem Management and Restoration Research Program (EMRRP) technical note is to document the validation study of the HEC-RAS-RVSM model for the Sacramento River reach and provide a user guide for applying this tool.

BACKGROUND: A dynamic riparian vegetation simulation module, RVSM.dll, has been developed for the HEC-RAS one-dimensional (1-D) model (Zhang et al. 2018). The HEC-RAS model was expanded to incorporate and assess riparian vegetation in the floodplain. Various processes and equations in RVSM and its integration with HEC-RAS have been critically tested and verified before, and the focus here is on the real-world application. The HEC-RAS-RVSM model was applied to the Sacramento River reach for modeling vegetation changes and predicting interactions between flow and riparian vegetation dynamics.

The Sacramento River, known as the Ecological Management Zone, supports a diverse aquatic, riparian, and terrestrial system. The river also serves societal needs for water supply and crop cultivation. Riparian restoration of the Sacramento River is highly desirable due to the ecological importance and degree of degradation of these areas. Since 1986, many restoration projects have been implemented to protect, restore, and enhance fisheries and riparian habitat of the Sacramento River (Viers and Hutchinson, 2008a). USBR has developed an integrated suite of predictive models that can be used to evaluate the effects of the proposed water supply management scenarios on the geomorphic conditions of the Sacramento River between Red Bluff and Colusa, California (U.S. Bureau of Reclamation (USBR) 2009; Greimann 2016). In the Sacramento River restoration study conducted by USBR, detailed information on cottonwood survival was collected at point bars in the Sacramento River downstream of Red Bluff at River Mile (RM) 192.5 and at 183 by California Department of Water Resources in 2005 and 2006. The site at RM 192.5 was a gravelly soil while the site at RM 183 was sandy; these sites provided a test of the desiccation function for both gravelly and sandy soils. In addition, the 
vegetation model calibration was conducted based on vegetation changes between 1999 and 2007 by geographic information system (GIS) vegetation mapping for RM 144 to RM 245, for a total of 100 miles. Mapping completed in 1999 was used for the simulated initial conditions. The 2007 vegetation mapping of the Sacramento River was used to validate the vegetation model. The comparison of simulated results of vegetation coverage and mapped results was a verification of Fremont cottonwood parameters and a calibration of parameters for mixed forest, Goodding's black willow, and sandbar willow.

A comprehensive validation of the HEC-RAS-RVSM model would require extensive datasets. Sacramento River datasets compiled by USBR were comprehensive and used to evaluate the capability of the HEC-RAS-RVSM model in predicting interactions between flow and riparian vegetation. River hydraulics, groundwater level, and five vegetation types of the study reach were simulated for an eight-year period (1999-2007). The HEC-RAS flow and groundwater were calibrated using 2005 observed river stage and groundwater level data for two sites (RM 192.5 and RM 183). Most vegetation parameters in HEC-RAS-RVSM were previously calibrated to field data and verified here with further adjustments.

The HEC-RAS-RVSM model was capable of simulating the time of establishment, the outcome of the cottonwoods' survival, and the elevation of recruitment. Model results agreed with observations indicating that the seedlings in the sandy soil would survive until the fall, but that no cottonwoods would survive in the gravelly soil. Model results also demonstrated that the HEC-RAS-RVSM model successfully reproduced the vegetation area's increase of cottonwood, riparian shrub, invasive species, and grass as well as the area decrease in mixed forest over the eight-year year period. By comparing cottonwood spatial expansion extracted from GIS vegetation mappings dated 1999 and 2007, the HEC-RAS-RVSM was able to predict cottonwood increase on certain point bars, but did not do well in simulating the fine-scale changes of cottonwood distribution around the edge of cottonwood patches. The model sensitivity analysis indicated that the height of capillary fringe and root growth rate are two critical parameters needed to be carefully calibrated with observed data.

HEC-RAS - RVSM: HEC-RAS is a public domain river hydraulic model. It contains five components: (1) 1-D steady flow water surface profile computations; (2) 1-D unsteady flow simulation; (3) 2-D unsteady flow simulation; (4) movable boundary sediment transport computations; and (5) water quality analysis through plug-in water quality modules. The latest version of the HEC-RAS model can be downloaded without change from the following website: http://www.hec.usace.army.mil.

The RVSM has been integrated into the 1-D unsteady flow engine in HEC-RAS. The details of HEC-RAS-RVSM can be found from Zhang et al. (2018). The overall flowchart of HEC-RASRVSM model is shown in Figure 1. In HEC-RAS-RVSM, the HEC-RAS model computes water surface elevation, discharge, average velocity, and energy slope of each cross section. The required input data include channel network connectivity, cross-section geometry, reach lengths, energy loss coefficients, etc. Boundary conditions are necessary to define discharge and water depth at the system endpoints; i.e., upstream and downstream. Lateral inflows and a variety of hydraulic structures can be prescribed within the model domain. 


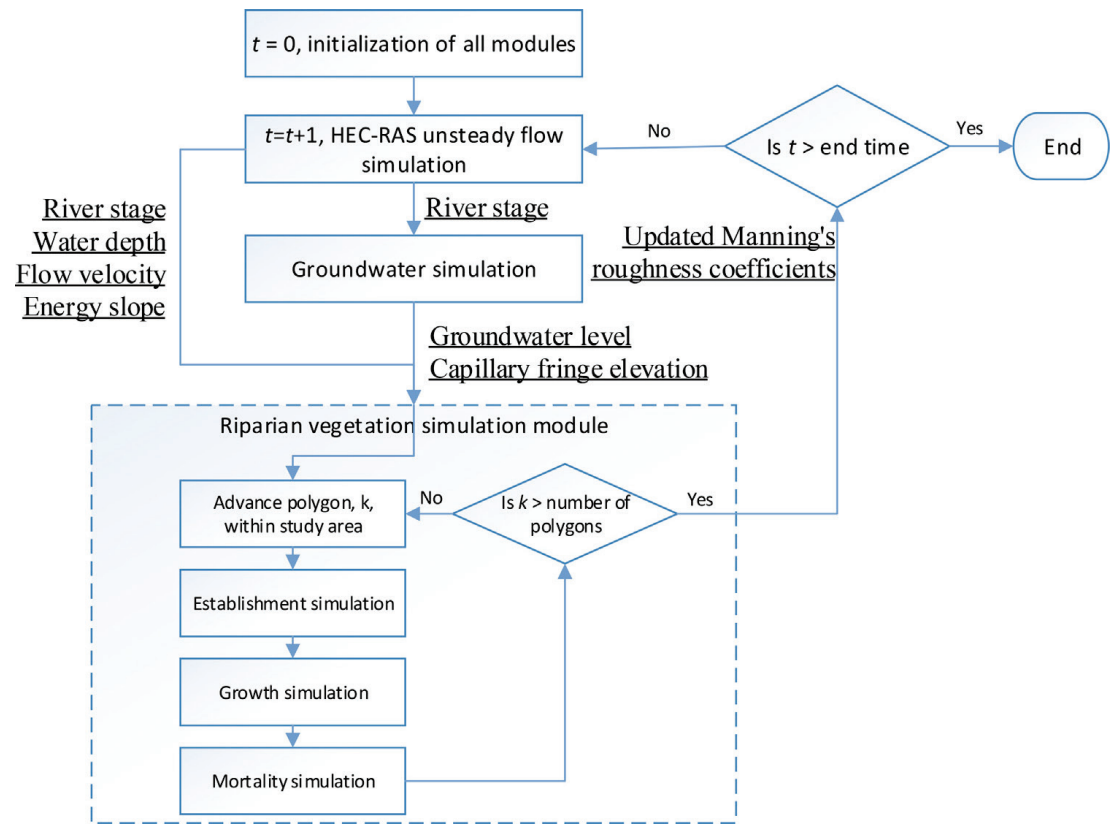

Figure 1. Flowchart of integrated HEC-RAS-RVSM model.

The RVSM simulates lifecycle of vegetation, including seed dispersal, seedling establishment, and plant growth and mortality in response to dynamic physical conditions (Zhang et al. 2018). During seed dispersal season, seeds are available to certain vegetation polygons in the model domain. Seedlings are only established within the vegetation polygons according to seed availability and suitability criteria. A seed germinates in user-defined germination seasons when groundwater capillary fringe reaches ground surface and no other vegetation types in the same polygon prevent the seed's germination. After the seed germination, plant growth is simulated by tracking growth of individual organs: root, stem, and canopy. The growth of plant root and stem is computed according to user-defined growth rates. The growth rates are specified for each month and age group. The root growth stops when reaching the maximum root depth or a userspecified depth with respect to groundwater table. The stem growth also stops when the maximum height is reached. The canopy height, width, and stem diameter are computed from empirical relationships with plant height.

Multiple mechanisms may result in plant mortality and should be removed from the model domain. The following mechanisms are included in RVSM: (1) Desiccation: two methods are available to simulate desiccation death. The root depth method supposes desiccation death occurs if the root tip is above the capillary fringe for a certain number of days. The cumulative stress method calculates water stress based on the groundwater level decline rate. This method is described in detail in the next paragraph. (2) Drowning: when vegetation is submerged for a certain number of days. (3) Scour: once flow velocity is greater than the maximum velocity plants can stand. (4) Competition: if other vegetation types within the same polygon outcompete this plant; e.g., invasive species reaching a certain age may displace or kill some native species. (5) Senescence: if a plant's age exceeds the maximum allowable age. The basic time step of the vegetation simulation is daily, but it is adjustable. 
The eleven vegetation roughness computation methods were included in the RVSM. They are $n$ UR curves, Kouwen and Li (1980), Huthoff et al. (2007), Cheng (2011), Baptist et al. (2007), Järvelä (2004), Freeman et al. (2000), Fischer and Fischenich (2000), Kouwen and FathiMoghadam (2000), Luhar and Nepf (2013), and Whittaker et al. (2015). The first two roughness methods are suitable for grasses, while the remaining nine methods suit for trees and shrubs. The model allows the user to select a roughness method for each vegetation type. The model also checks if vegetation is partially or completely submerged based on flow depth and plant height, and then switches to a corresponding roughness equation. If vegetation is not submerged or the flow depth and velocity are 0 , Manning's $n$ value is set to 0 . A detailed description of the HECRAS-RVSM can be found in Zhang et al. (2018).

APPLICATION OF HEC-RAS-RVSM MODEL: The HEC-RAS-RVSM was applied to the Sacramento River, California, between Red Bluff Diversion Dam (RM 250) and Colusa (RM 143). Figure 2 shows the Sacramento River reach and its location. The Sacramento River is integral to the aquatic and riparian habitat as well as to the water supply of California; it is necessary to understand the impact of alternative water supply management on the Sacramento River corridor. This area, known as the Ecological Management Zone, supports a diverse aquatic, riparian, and terrestrial system. It also serves societal needs for water supply and crop cultivation. Since 1986, many restoration projects have been implemented to protect, restore, and enhance the fisheries and the riparian habitat of the Sacramento River (Viers and Hutchinson, 2008a). The USBR has developed a suite of models for analyzing the effect of alternative flow operations on the riparian corridor of the Sacramento River (USBR 2009).

Data sets compiled by USBR were used to develop a HEC-RAS-RVSM model for the Sacramento River reach and to evaluate its capability in predicting interactions between flow and riparian vegetation. The Sacramento River HEC-RAS-RVSM model was developed to predict riparian vegetation change in response to flow regime, particularly the spatial change of cottonwood distribution over the eight-year period (1999-2007). 


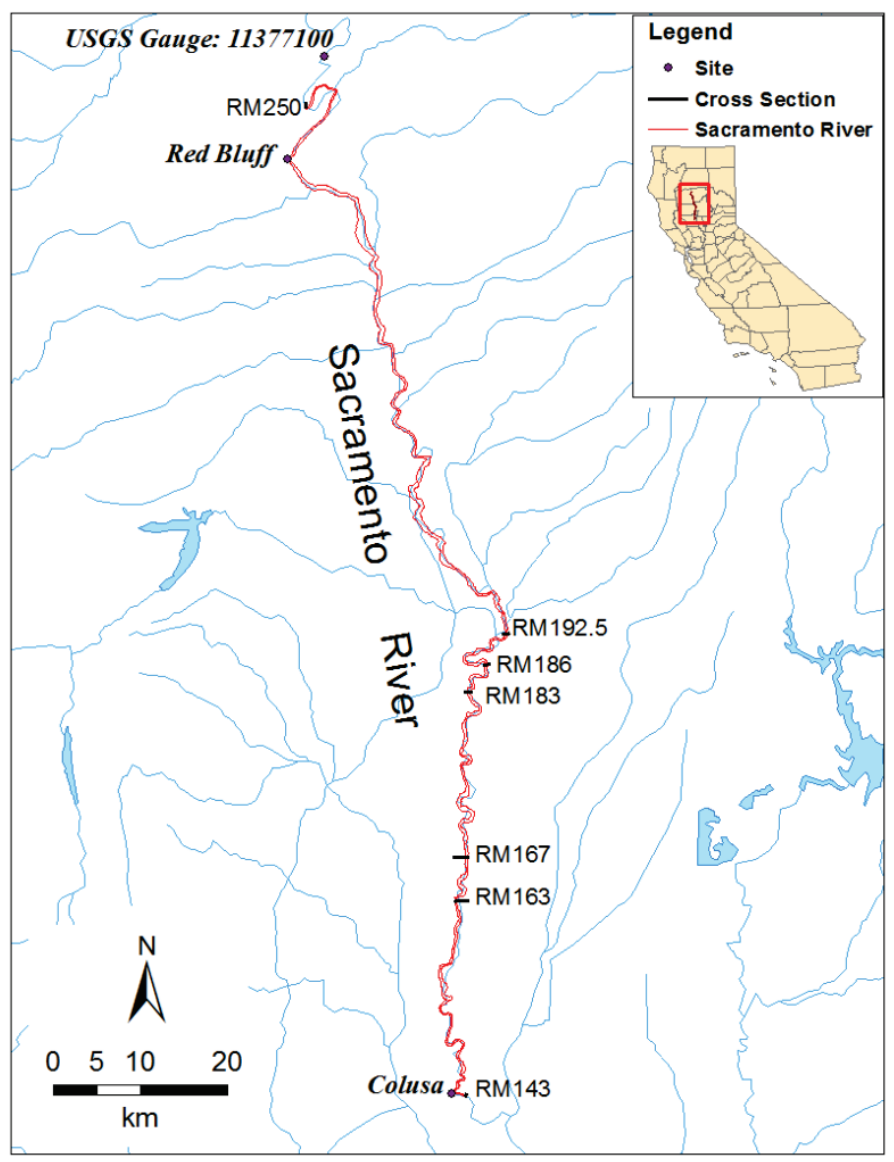

Figure 2. Study reach of the Sacramento River.

HEC-RAS Flow Model. A Sacramento River HEC-RAS model was originally developed and calibrated by the USACE (2002). This model includes 342 cross sections. To assess the model performance with regard to riparian vegetation predictions, acceptable simulation of river hydraulics is important. The Sacramento River HEC-RAS model was further refined and calibrated to support the vegetation simulation. The HEC-RAS model domain was interpolated into 1063 cross sections and updated to the latest HEC-RAS 5.0.4. The model simulated flow and water elevation along the river reach from 10/01/1999 to 10/01/2007. Observed flow at USGS Gage No. 11377100 Sacramento River above Bend Bridge, near Red Bluff, California, was used as the model's upstream boundary condition. Figure 3 shows eight years' of observed hydrograph for the upstream flow boundary. The rating curve at Colusa, California, was used as the model's downstream boundary condition. No tributary was included in the hydraulic model. 


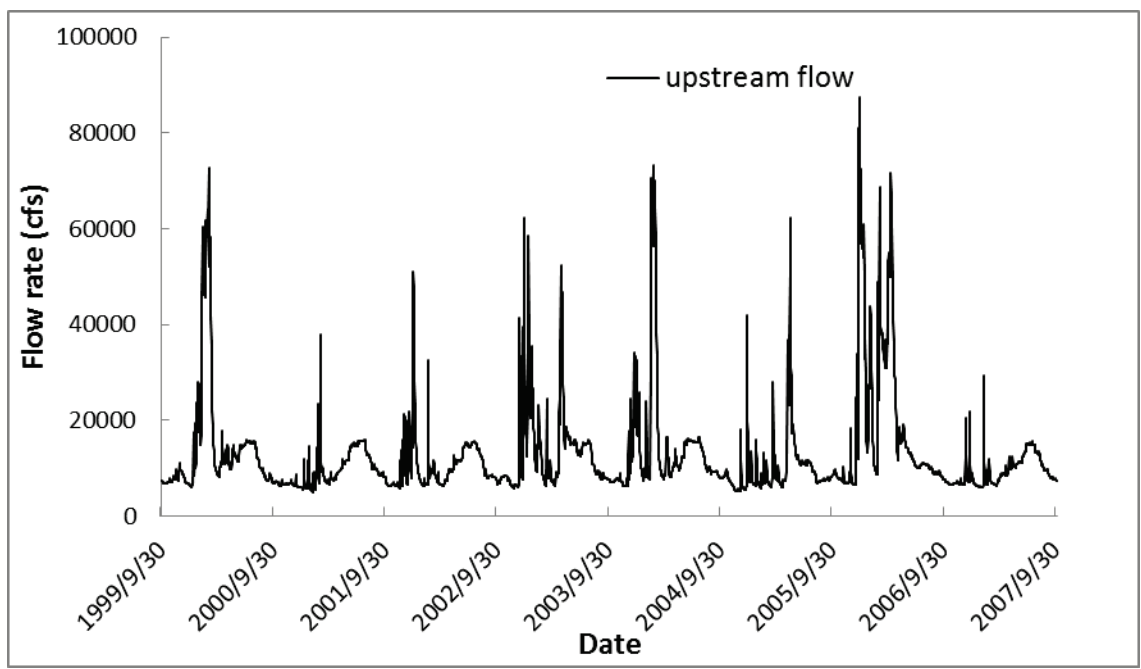

Figure 3. Upstream flow boundary of the HEC-RAS Sacramento River model.

Observed surface water elevation at RM 192.5 and RM 183 in 2005 were used to calibrate the HEC-RAS hydraulic model. The calibrated roughness coefficients of the main channel vary between 0.02 and 0.04, while those of floodplains are in the range of 0.029 to 0.2.

Groundwater Model. The measured groundwater level at RM 192 from June to October in 2005 was used to calibrate the saturated hydraulic conductivity of groundwater model. Based on the study of USBR (2009), gravel is the primary bed material in the study reach, although there are some sandy bars. A uniform hydraulic conductivity for gravel, 100,000 ft/day, was applied to the model domain.

The height of capillary fringe in the groundwater model is used to compute the capillary fringe affecting seedling establishment in the RVSM. The height of the capillary fringe at the study site is unknown, but some studies on gravel-bed rivers (Mahoney and Rood, 1998; Meier and Hauer 2010) suggest that it often extends 1-2.5 ft. Therefore, in this study, the height of capillary rise was set to $1 \mathrm{ft}$.

During dry periods with no flow in the channel, the minimum groundwater elevation $\left(h_{\text {min }}\right)$ can be influenced by groundwater flow conditions outside the boundaries of the model. These conditions are generalized by assigning a lower limit $\left(h_{\min }\right)$ to groundwater elevation for lands within the model. A second limit, $h_{\max }$, is assigned to the water surface on lands behind levees. Unless the levee is breached, surface water depth behind a levee is influenced more by drainage patterns of adjacent lands than by the surface water of the river. Both $h_{\min }$ and $h_{\max }$ are values in feet with respect to the ground elevation.

Vegetation Model. The riparian zone for the Sacramento River HEC-RAS model domain is first discretized into a vegetation computation mesh, including an array of parallel slice polygons along the channel bank. Within the polygon, characteristics of hydraulics, groundwater, and vegetation are treated as a homogeneous computation unit in RVSM. In this study, 60 slice polygons were created along each cross section for the main channel, while 20 slice polygons were created respectively for the left and right floodplains. Vegetation polygons in the main 
channel were much denser than those on floodplains because riparian seedlings such as cottonwood grow in narrow strips close to the water edge. The average length of the vegetation polygons is about $500 \mathrm{ft}$, whereas the width of vegetation polygons in the main channel is 10-60 $\mathrm{ft}$, and their width on the floodplains is $50-500 \mathrm{ft}$. A total of 106,300 vegetation slice polygons were created for the Sacramento River vegetation model. Figure 4 shows partial vegetation computation mesh with an assigned slice polygon id for the Sacramento River reach.

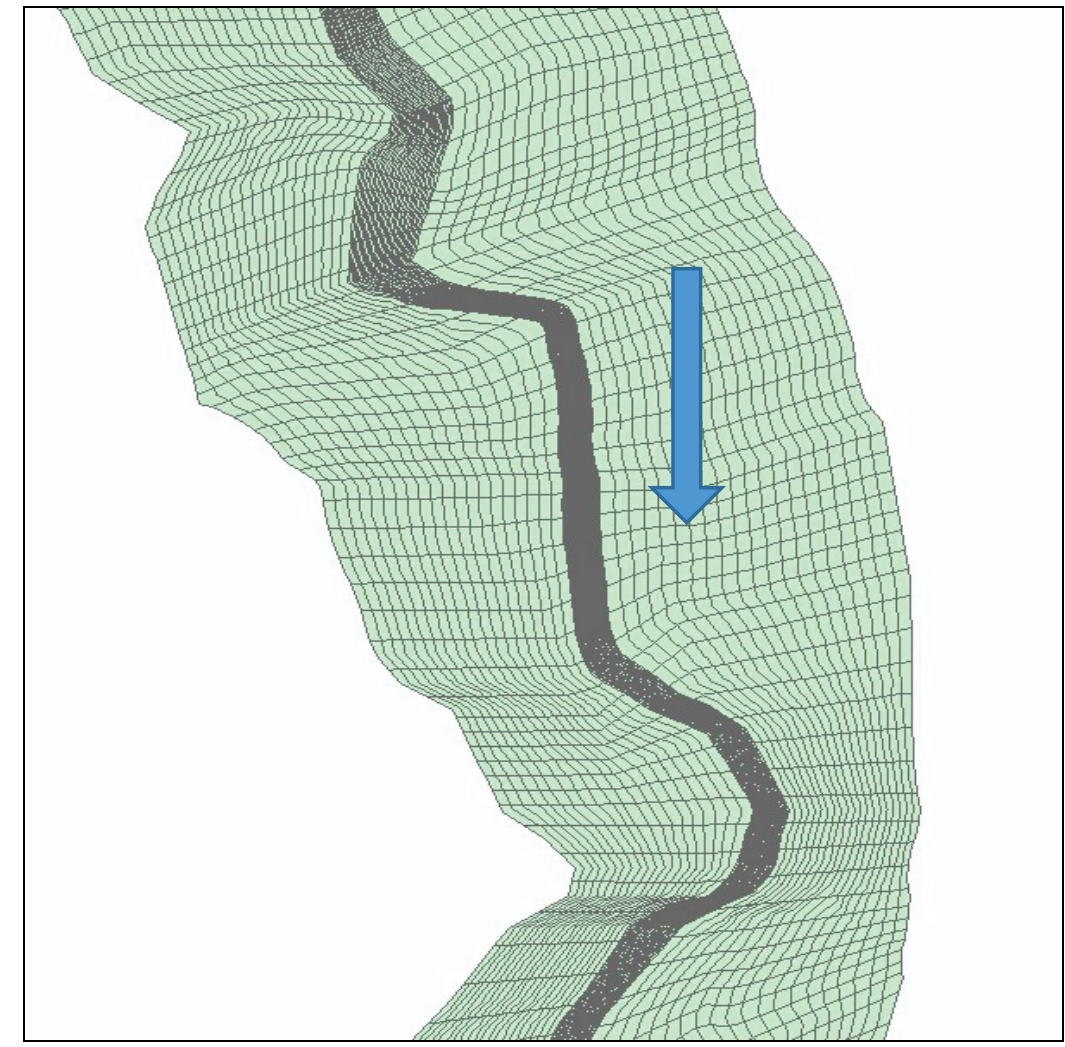

Figure 4. Partial vegetation computation mesh with assigned slice polygon id for the Sacramento River reach.

Five main vegetation types were simulated based on approximately 20 vegetation species of the Sacramento River reach. Simulated vegetation types include Fremont's cottonwood (Populus Fremontii), mixed forest, riparian shrub, invasive species and grass. Mixed forest is a combination of valley oak (Quercus lobata), California sycamore (Platanus racemosa), black walnut (Juglans nigra), and box elder (Acer negundo). Riparian shrub was an alliance of mixed willows, Goodding's black willow (Salix gooddingii), riparian scrub, and blackberry scrub (Rubus). Invasive species include giant reed (Arundo donax) and tamarisk. Parameters of germination, growth, and mortality were defined based on individual vegetation type simulated in RVSM. Additionally, "no grow" was defined as a vegetation type to account for the agricultural, residential, and industrial lands on floodplains.

GIS vegetation mapping dated in 1999 was used to assign initial conditions of the vegetation model. The initial ages of cottonwood and mixed forest were set to 40-year-old, riparian shrub 
was set to 5-year-old, invasive species were set to 2-year-old, and grass was designated as 1year-old.

After initialization, the model tracks growth of the assigned plants, in addition to computing new vegetation (germination) when conditions are suitable. Every VIV record translates a mapped community to the modeled vegetation types. For example, the GIS shapefile may contain 30 mapped categories of land use, which are translated into the 8 modeled vegetation types using the VIV records. For each mapped community, the VIV records associate the GIS identifier, the age, and the density. The ability to assign density of each plant type to represent a mapped community is an improvement to the computing process in RVSM. Density is input as a decimal representing the percent of points in the mapped polygon. For a density of 0.1 or 10 percent, the associated age and type of vegetation is assigned to 1 point out of every 10 points in the mapped polygon. A vegetation type excluded from a mapped community was assigned an age of 0 . Areas described as "Riparian Scrub" may have sparsely located grasses, occasional shrubs, and a rare tree.

All other vegetation types in the riparian scrub VIV record were assigned an age of 0 . Descriptions of the mapped communities and aerial photos were used to match communities with vegetation types, and to assign average densities and representative ages to vegetation types.

Vegetation Parameters. Cottonwood seedling density at two point bars of RM 192.5 and RM 183 monitored in 2005 and Cottonwood seedling elevation at two transections of RM 192 monitored in 2006 were used to calibrate cottonwood seedling establishment. Two sets of GIS vegetation mapping in 1999 and June 2007 (Viers and Hutchinson, 2008b) were used to calibrate the establishment, growth, and survival of multiple vegetation types. Temporal changes in the vegetated area from the 1999 and 2007 mapping were compared with changes in vegetated area computed by the HEC-RAS-RVSM model. Moreover, the model is further validated by comparing spatial change of cottonwood from the 1999 and 2007 mapping to predicted spatial change of cottonwood for the same period. Since vegetation field survey and lab experiment data of the Sacramento River reach are mainly about cottonwood, most calibration efforts of this study focused on cottonwood.

Parameters in the RVSM input file are often found in journal articles on site studies of mature plants or laboratory investigations of new seedlings. Occasionally, a range of values for a specific plant could be found from multiple sources, but the range in values often appeared related to regional and climatic factors. Verification and sensitivity simulations helped to identify influential parameters that were addressed further in model calibration studies using field or mapping data. Calibration helped define parameters within the range of values initially considered.

Germination Parameters (MPR) parameters include (1) time required for seed germination; (2) maximum time allowed for germination from soil wetting; (3) capillary fringe area for germination; and (4) height above ground water surface that germination can occur.

In a study of cottonwood establishment and survival, Borman and Larson (2002) found that the cottonwood seedling crop would fail if the surface dried within several days after germination. The initial seedling root growth was slow, and the surface soil needed to be damp for the first 
one to three weeks after germination. Germination usually occurred between 8 and $24 \mathrm{hr}$ after a cottonwood seed fell on a moist surface. Cottonwood seed germination is assigned a value of $12 \mathrm{hr}$ in this model. The maximum number of days between germination and the time when the water table is within a specified distance of the ground surface is also a required model input. The maximum number of days is set to 2 days, which assumes the soil will dry out 2 days after the river recedes below the specified elevation. Height above the groundwater surface is set to the capillary fringe height. The capillary fringe height is approximately $1 \mathrm{ft}$, although this may vary in the reach. Germination is assumed not to occur below the groundwater table.

In this study, airborne seed dispersal season selected for cottonwood was May 1 to July 1. These dates were based on a seed dispersal survey conducted by the California Department of Water Resources (CDWR) (2005). One of the most variable parameters is seed dispersal season for mixed forest. Mixed forest includes Oregon ash (Fraxinus latifolia), box elder (Acer negundo), California sycamore (Platanus racemosa), and valley oak (Quercus lobata), although other woody species may be grouped in this mapping community. These woody species share similar traits like water and shade tolerance but have wider variation in germination seasons. Oregon ash produces airborne seeds in September and October that are viable for a year. Box elder also produces airborne seeds in the fall that are dispersed throughout the winter, producing a range of germination periods. Valley oaks germinate from acorns, and the root can begin growing in December several months before the shoot appears, giving the taproot a 3-feet start on growth towards the water table (see http://phytosphere.com/oakplanting/acorns.htm). The germination season for woody species was calibrated to June 15 through July 10 to more closely represent the areas of GIS mapped vegetation. The longer germination season was producing excess areas of mixed forest in the model.

\section{Growth Parameters:}

Stalk Growth Rate (GST). Values for stalk growth rate are defined by plant age for each month of the year. Stalk growth rate is not relevant to other computations in the model, but the rate does control the appearance of the stalk in the cross-section window during the simulation.

Maximum Height of Stalk (GSM). When the maximum plant height is reached, the plant stops growing. This value is primarily used for graphical observations of cross sections during the simulation. Varying stalk heights and colors allow the observer to distinguish between plant types.

Root Growth Rate (GRT). Values for root growth rate are assigned by plant age for each month of the year. If root growth can be sustained at the same rate as the drop in water table elevation, the roots can continue to supply the plant with moisture from the groundwater. Values for cottonwood root growth used in the model were based on several published investigations. Morgan (2005) and Cederborg (2003) observed the average growth rate for roots to be approximately 0.5 centimeters per day $(\mathrm{cm} / \mathrm{d})$ with a maximum of $1.4 \mathrm{~cm} / \mathrm{d}$. Roberts et al. (2002) reported an average rate of $2.2 \mathrm{~cm} / \mathrm{d}$, with a maximum rate of $3.2 \mathrm{~cm} / \mathrm{d}$. In the dessication study conducted by SEI, it was found that seedlings could generally sustain a water table drop of 0.5 $\mathrm{cm} / \mathrm{d}$ indefinitely. These results indicate that $0.5 \mathrm{~cm} / \mathrm{d}$ is a root growth rate that does not exert stress on the plant. A plant can have faster root growth rates for a period of time, but this rate of growth expends plant energy reserves and exerts stress on the plant, eventually causing 
mortality. Therefore, the root growth parameter is best thought of as a "no-stress" root growth value.

Maximum Depth of Root below Water Table before Growth Stops (GRS, GRT). The depth below the groundwater table where the root growth stops was assumed to be $0.1 \mathrm{ft}$ for Fremont cottonwood and Goodding's black willow. Narrow leaf willow and invasive plants have better coping mechanisms for inundation; consequently, their roots are allowed to extend to $0.2 \mathrm{ft}$ below the water surface before growth stops.

Depth, Maximum Depth of Root Growth (GRS, GRT). Maximum root depth is one of the most sensitive parameters in the model for defining survival between different vegetation types. In addition to groundwater and moisture availability, a second factor for root depth is soil type, with densely compacted soils or rock restricting the extension of roots and aeration. A third factor is aeration since roots need oxygen to transpire. It is assumed, however, that maximum depths can be attained in the alluvial soils being modeled. Aeration is addressed with inundation tracking described under plant mortality. Therefore, the primary factor defining root depth in the model is groundwater depth.

The root-depth parameter (GRT_Depth) represents different root structures with taproots, rather

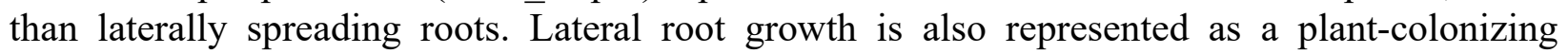
mechanism under model germination. Rhizomes of the invasive plant giant reed tend to grow laterally, and narrow leaf willow roots, to a lesser extent, also grow laterally. Lateral root growth development occurring with tap root development for woody species may reduce plant reliance on the groundwater table. The growth of a taproot appears to be most prominent in young plants up to about six years. Stress on plants is based on proximity to groundwater. Subsequently, calibration studies can indicate root depths to be used in the model and may represent the deepest values reported in the literature. Zimmermann's (1969) investigation on plant ecology in Southeastern Arizona presents root depths for cottonwood, black willow, sycamore, and alder growing in areas where groundwater is generally less than $40 \mathrm{ft}$ below the surface, but older trees might depend at least part of the year on moisture in the alluvium. Actual root depths reported were $7+\mathrm{ft}$ for cottonwood, $7 \mathrm{ft}$ for black willow, and 15+ ft for Hackberry. Horton et al., (2001) reported that Fremont cottonwood was commonly found in areas where groundwater was 0.5 to 4 meters deep. Goodding's black willow is more shallow-rooted than Fremont cottonwood (Stromberg et al. 1996). Adjusted root depths for native plants in this model after calibration are Fremont cottonwood, $24 \mathrm{ft}$; mixed forest, $20 \mathrm{ft}$; Goodding's black willow, $22 \mathrm{ft}$; and narrow leaf willow, $8 \mathrm{ft}$.

Tamarix has deep roots (Zimmerman 1969 and Horton et al. 2001), but other invasive plants like giant reed and phragmites have shallow rhizomes that are easily undercut in secondary flows similar to wetland plants like California bulrush or cattail. The single vegetation type for invasive plants as used in this study is representative of giant reed and other shallow-rooted plants, but this vegetation type is not a good representation of tamarix. The calibrated root depth for invasive plants in the Sacramento model is $5 \mathrm{ft}$. 


\section{Mortality Parameters:}

Death by Inundation (DTM). Inundation mortality occurs when the root crown of a cottonwood is submerged by a specified depth and for an extended period of time. The threshold time of inundation and the depth of inundation above the root crown can be entered as a function of age. Hosner (1958) found that plains cottonwood seedlings will survive 8 days of inundation, but most die after 16 days. After a few years of growth, cottonwoods may become more resistant to drowning; however, prolonged inundation will still kill most plants, and inundation of more than a few weeks will stress cottonwoods (Neuman et al. 1996). In a study by Stromberg et al. (1993), inundation of saplings (10 cm at $1 \mathrm{~m}$ height) were examined in the Sonoran desert where 2-year, 5-year, and 10-year floods had occurred. Flow depths varied from 0.4 to $2.1 \mathrm{~m}$. Goodding's black willow had greater rates of survival than Fremont cottonwood. Survival of poles and saplings declined sharply when depths exceeded $1.5 \mathrm{~m}$ and ranged from 30 percent to 78 percent for saplings; 73 percent to 93 percent for pole trees; survival was 100 percent for mature trees. Auchincloss et al. (2010) determined that Fremont cottonwood seedlings had 78 percent and 50 percent survival for one week and two week submergence of seedlings. Mortality increased linearly for seedlings based on days of complete submergence at a rate calculated by equation 63. Auchincloss et al. (2010) also reported that greater depths of submergence were more detrimental than shallow depths of submergence. In addition, seedlings had greater survival rates in colder water, fluctuating between 11 and 18 degrees Celsius in contrast to temperatures of 18 to 24 degrees Celsius.

Type of Desiccation Simulation (YMT). There are two types of desiccation mortalities that can be selected: a root-depth method and a cumulative water-stress method. Water-stress values apply specifically to young cottonwood plants and have not been developed for other vegetation types or ages. The root stress method was used in the cottonwood study and the water stress method was developed during multi-vegetation studies.

Desiccation by Root Depth (YTM). The root depth method depends on separation between the root tip and the capillary zone of the water table for a specified number of days to determine when desiccation will occur. Fremont cottonwood and Goodding's black willow have droughtcoping mechanisms as adult plants; the coping mechanisms increase the plants' resilience to drought stress. Horton et al. (2001) report on the canopy dieback mechanism that allows plants to reduce water consumption through branch sacrifice during dry periods. Giant reed is assigned a high resilience (more days before removal) in this simulation because of its rhizome development that allows the plant to extend laterally to a water source. Narrow-leaf willow is less tolerant of drought than Fremont cottonwood.

Desiccation by Cumulative Water Stress (YWT). The second method, based on water stress of young plants, was added following laboratory desiccation studies of cottonwood plants conducted by SEI. Cumulative stress imposed on the young plant (measured as a desiccation rate) is tracked until a user-specified water stress is reached and the plant is removed. Desiccation rates for the water stress method are provided for two soil types. These values were developed based on the RHEM studies. Plants are assumed to die from desiccation when the stress parameter exceeds a user-specified value. In the study conducted by SEI, cottonwoods generally perished when the water stress parameter exceeded 0.6 . 
Months Desiccation is Allowed (YMN). This record can be used to assign dormant months when desiccation will not harm the plant.

Ice-Scour Mortality (IMT). This process is not simulated in this study.

Mortality by Senescence (AMT). Plants that reach a maximum age are removed from the model. Mortality by Senescence is not simulated in the Sacramento model due to the relatively short time period (seven years or less) of the simulations.

During model calibration and validation, agreement between modeled results and observed data was evaluated visually and quantitatively. The primary calibration parameters for the Sacramento River vegetation model are listed in Table 1.

\begin{tabular}{|c|c|c|c|c|c|}
\hline Vegetation type & $\begin{array}{l}\text { Fremont's } \\
\text { cottonwood }\end{array}$ & $\begin{array}{l}\text { Mixed } \\
\text { forest }\end{array}$ & $\begin{array}{l}\text { Riparian } \\
\text { shrub }\end{array}$ & $\begin{array}{l}\text { Invasive } \\
\text { species }\end{array}$ & Grass \\
\hline Germination start, end date (Julian day) & 120,170 & 144,162 & 129,181 & 60,210 & $\begin{array}{l}31 \\
150\end{array}$ \\
\hline Root growth rate for seedlings (ft/d) & 0.00656 & 0.0165 & 0.05 & 0.082 & $\begin{array}{l}0.004 \\
2\end{array}$ \\
\hline Maximum root depth $(\mathrm{ft})$ & 20 & 20 & 9 & 5 & 0.5 \\
\hline Scour velocity (ft/s) to cause seedling death & 2 & 2 & 2 & 3 & 0.75 \\
\hline Drowning days (d) to cause seedling death & 15 & 12 & 30 & 60 & 5 \\
\hline Method to consider for desiccation death & $\begin{array}{l}\text { Cumulative } \\
\text { stress }\end{array}$ & $\begin{array}{l}\text { Root } \\
\text { depth }\end{array}$ & Root depth & $\begin{array}{l}\text { Root } \\
\text { depth }\end{array}$ & $\begin{array}{l}\text { Root } \\
\text { depth }\end{array}$ \\
\hline Desiccation days (d) to cause seedling death & NA & 2 & 7 & 10 & 180 \\
\hline $\begin{array}{l}\text { Relationship between water table decline } \\
\text { rate (ft/d) and desiccation stress (unitless) }\end{array}$ & $\begin{array}{ll}-3.28, & -1.51 \\
-0.0328, & -0.021 \\
0.0, & -0.013 \\
0.0328, & 0.009 \\
0.0656, & 0.032 \\
0.0984, & 0.115 \\
3.28, & 5.9\end{array}$ & NA & NA & NA & NA \\
\hline
\end{tabular}

Note: NA in the table means this parameter was not used in the vegetation model. If root depth method is selected, desiccation death is controlled by desiccation days; otherwise, the relationship between the water table decline rate and desiccation stress is used and desiccation death is controlled by whether cumulative stress exceeds 0.6.

Model Results and Comparisons with Observed Data. The HEC-RAS-RVSM model was run for an eight-year simulation period from 1999 through 2007. The model results include flow discharge and river stage as well as a variety of vegetation outputs. This section presents HEC-RAS-RVSM modeled results and a comparison with field measurements for flow and vegetation compiled for the Sacramento River.

Simulated River Stages and Groundwater. Figure 5 shows the comparison between HECRAS simulated and observed river stage at RM 192.5 and RM 183 in 2005. Simulated river stage at the two sites matches observed river stage very well. The root mean square errors of river stage at RM 192.5 and RM 183 for the simulation period are $0.28 \mathrm{ft}$ and $0.27 \mathrm{ft}$, respectively. 

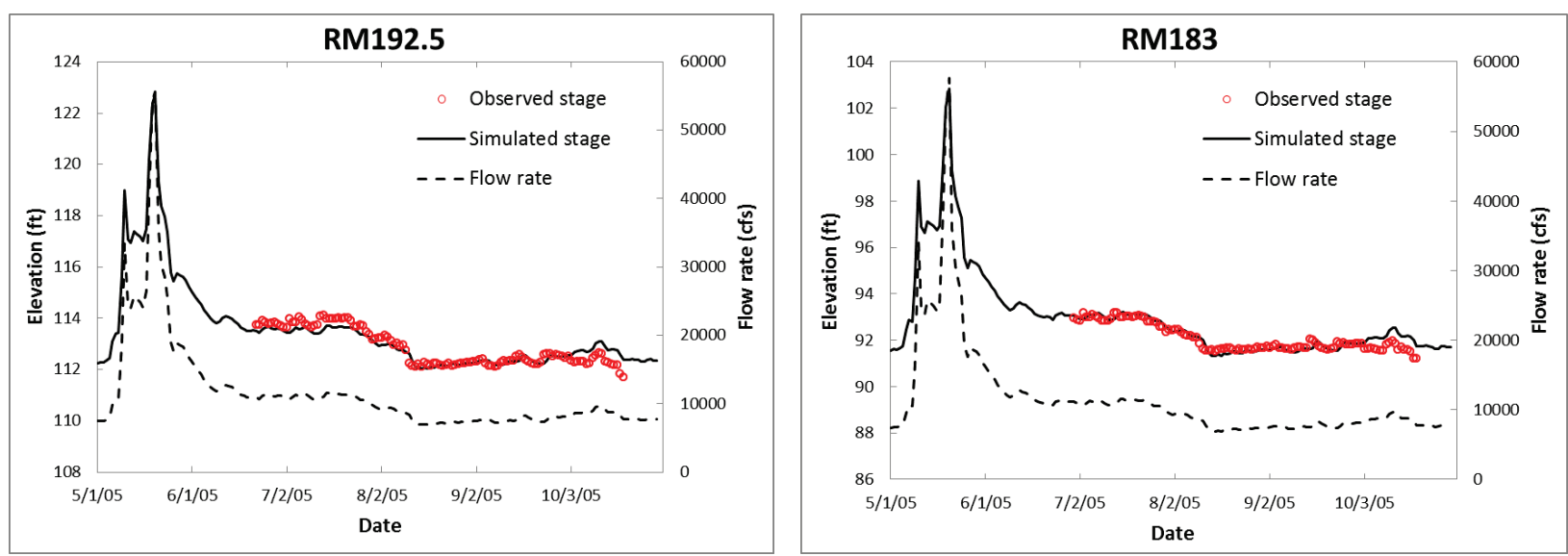

Figure 5. Simulated and observed river stage at RM 192.5 and at RM 183.

To understand vegetation response to groundwater level, the team analyzed the water table along the river. Water table depth was measured weekly during the summers of 2005 using groundwater monitoring wells along transects in RM 192.5. Figure 6 presents the simulated and observed groundwater level at approximately $1000 \mathrm{ft}$ from the water edge of cross section RM 192. Observed water surface elevation at RM 192 is also shown in Figure 6. The groundwater level at RM 912 is pretty close to water surface elevation, which indicates groundwater level responds quickly to surface water change.

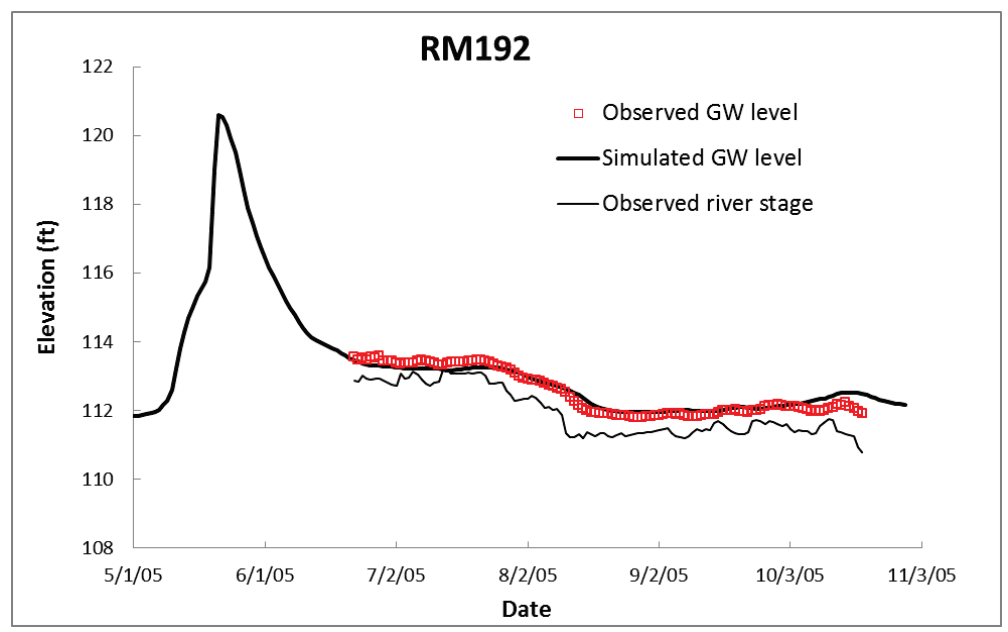

Figure 6. Simulated and observed groundwater level at RM 192.

Simulated Vegetation. Simulated cottonwood seedling areas at RM 192.5 and RM 183 from May to September in 2005 are compared with observed cottonwood density data in Figure 7. The RVSM did not compute plant density; rather, the RVSM only tracked whether a vegetation type survives in vegetation polygons, so simulated seedling areas were used to compare with observed seedling density. In general, the change trend of seedling density is consistent with that of seedling area during seed germination season. 

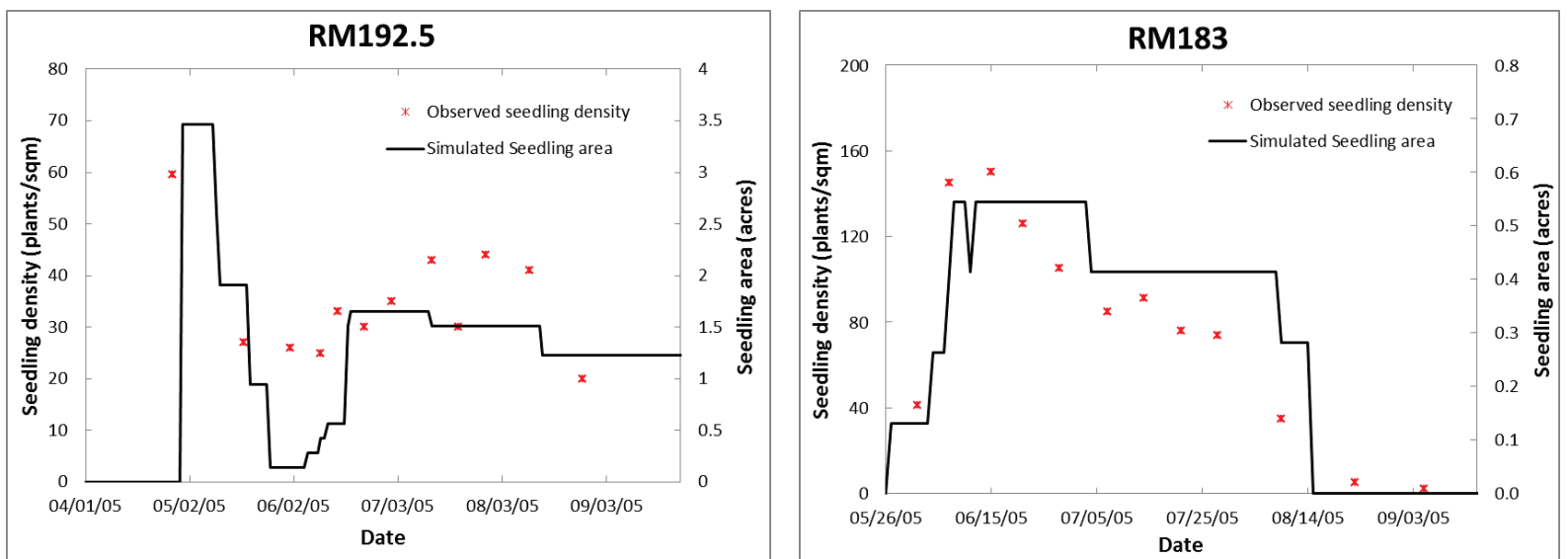

Figure 7. Comparison between simulated cottonwood seedling area and observed seedling density at RM 192.5 and RM 183.

Figure 7 shows that the change trends of RVSM-simulated seedling area at both RM 192.5 and RM 183 are in agreement with that of observed seedling density. There were two seedling peaks and two falls following each peak from April to August. The first seedling peak observed at RM 192.5 occurred on April 27, while the simulated peak took place in early May, a small time lag compared with the observed time. The second observed seedling peak was in July, but the second simulated peak appeared in middle June. The difference was caused by the start and end dates of the germination season defined in the model, e.g., April 30- June 19 (Table 1). This information was derived from cottonwood seed release monitoring by CDWR (2005). However, the actual seed dispersal in 2005 exceeded this period and a large-scale seed release persisted for July (Greimann and Fotherby 2012).

Both observed seedling density and RVSM simulated seedling area at RM 192.5 declined significantly in middle May due to flood scour and the rapid water level decline following this flood (see Fig. 7). The second decrease of seedling density and area started from August at RM 192.5 and from July at RM 183 and was relatively small since both surface water level and groundwater level receding rates in July and early August were small (Fig. 7 and Fig. 8). From middle August, river stage further declined and stayed at a low level afterward. This process caused the majority of seedlings to die at RM 183. However, a fraction of seedlings survived to the next year at RM 192.5. Although the river stage and groundwater change rates were similar at RM 183 and RM 192.5, the change trends of seedling density and area between the two sites were different. This may be due to their different cross section geometries; the bank slope at RM 192.5 is gentler than that of RM183.

Figure 8 shows that the RVSM simulated and observed maximum and minimum cottonwood seedling elevation above low water in 2006 on a gravel soil bar and on a sandy soil bar. Observed data at the two sites suggest that elevation of cottonwood seedling in both gravel soil and sandy soil descended closely following the decrease of river stage. The model also captured this pattern of temporal change. Furthermore, the RVSM-simulated seedling elevation on a gravel soil bar matches the observed elevation much better than that on a sandy soil bar. The height of capillary fringe used in this study is $1 \mathrm{ft}$, a typical value for a gravel bar. It is too low for sandy soil. The height of capillary fringe for sandy soil is often higher than $1 \mathrm{ft}$. According to 
Harr (1962), the height of capillary fringe for fine sand is 1.15-2.3 $\mathrm{ft}$. Comparing the observed seedling elevation above low water at two sites in Fig. 10, led to the conclusion that the seedling elevation on the sandy soil bar is higher, and the distance between maximum and minimum seedling elevation is much wider than these on the gravel soil bar. In particular, the observed maximum seedling elevation above low water in sandy soil is about $1 \mathrm{ft}$ higher than that elevation in gravel soil. This implies that cottonwood seedling elevation is very sensitive to the local soil's height of capillary fringe. According to the study of Meier (2008), the height of capillary rise is highly variable at fine spatial scales, which should result in fine-scale vegetation patchiness.
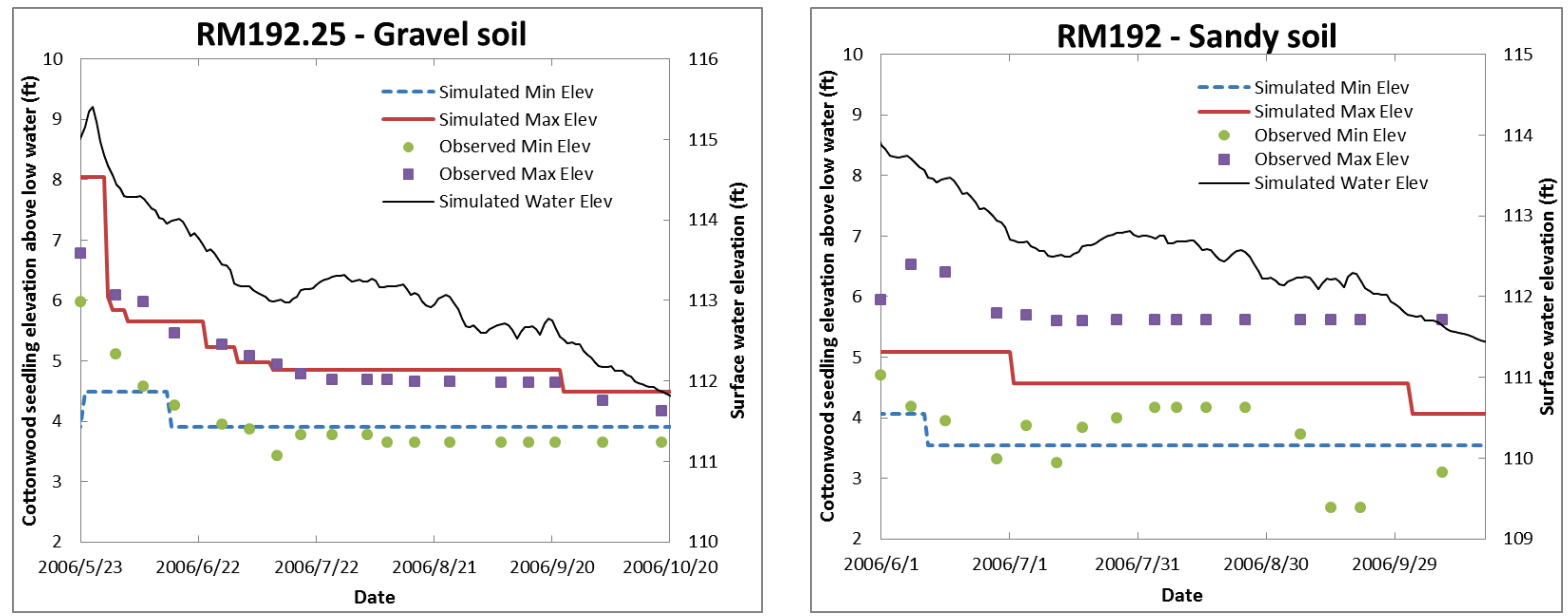

Figure 8. A comparison between simulated and observed cottonwood seedling elevations on a gravel soil bar and those on a sandy soil bar in 2006.

The computed and mapped acreage changes of the five vegetation types between 1999 and 2007 are presented in Table 2. If two plant types are growing at the same polygon in the model, the same area is attributed to both vegetation types. If vegetation types are combined, this creates double counting in the modeling area measures; consequently, the vegetated area was replaced with a ratio of change (vegetated area from year 8: vegetated area in year 1) to compare results. The ratio for associated vegetation types from the model simulations were compared to the ratio for the matching community from vegetation mapping.

The results indicate that the Sacramento River vegetation model was able to predict the increasing or decreasing trends of all major vegetation types over eight years. In both mapping and modeling studies, the coverage increases between 1999 and 2007 for five vegetation types except mixed forest. The model computed area change ratio was smaller for cottonwood and mixed forest, and was larger for invasive species than the mapped change ratios. The model computed change ratio for riparian shrub and grass was close to mapped values.

The computed area change of cottonwood was a 14\% increase over the eight years, lower than the mapped ratio. The vegetation maps show that the cottonwood area increased by $35 \%$ between 1999 and 2007, but a 25\% increase was converted from deciduous fruits, nuts, and field crops. The riparian vegetation restoration implemented during the simulation period (Golet et al. 2008) probably derived this type of land conversion. In this study, deciduous fruits, nuts, and field 
crops were simulated as the "nogrow" vegetation type; therefore, no other vegetation types can grow in the space occupied by "nogrow." However, the computed increase ratio is reasonably good when this type of land conversion was excluded. The simulated area of mixed forest was larger than that measured from the mapping. Mapped riparian areas include riparian scrub and riparian vegetation and simulated riparian areas are Goodding's black willow and sandbar willow. Combined riparian scrub and riparian vegetation (mapping) have a $40 \%$ increase, similar to riparian model results for Goodding's black willow and sandbar willow that predict a $35 \%$ increase.

The above model result indicates that the HEC-RAS-RVSM model can be used to predict relative changes of major vegetation types over a long-term period. The tool will be helpful for quantifying impacts of flow management alternatives and ecosystem restoration projects on riparian vegetation.

\begin{tabular}{|c|c|c|c|c|c|c|}
\hline & Year & Cottonwood & $\begin{array}{l}\text { Mixed } \\
\text { forest }\end{array}$ & $\begin{array}{l}\text { Riparian } \\
\text { shrub }\end{array}$ & $\begin{array}{l}\text { Invasive } \\
\text { species }\end{array}$ & Grass \\
\hline \multirow{3}{*}{$\begin{array}{l}\text { Area from } \\
\text { mapping } \\
\text { (acre) }\end{array}$} & 1999 & 5319 & 8842 & 3310 & 77 & 3169 \\
\hline & 2007 & 6621 & 6621 & 4127 & 122 & 4280 \\
\hline & Change ratio & 1.35 & 0.75 & 1.25 & 1.59 & 1.35 \\
\hline \multirow{3}{*}{$\begin{array}{l}\text { Area from } \\
\text { model } \\
\text { (acre) }\end{array}$} & 1999 & 5308 & 8827 & 3275 & 72 & 3233 \\
\hline & 2007 & 6028 & 8246 & 3891 & 153 & 4609 \\
\hline & Change ratio & 1.14 & 0.93 & 1.19 & 2.12 & 1.42 \\
\hline
\end{tabular}

The model was further validated by comparing the mapped and predicted spatial changes of cottonwood from 1999 to 2007. The comparison indicates that the model was able to capture an evident cottonwood coverage increase on certain point bars even though the predicted locations may not have been exactly accurate. For example, Fig. 9a shows that at the reach between RM 183.5 and RM 186, the predicted spatial location of cottonwood increase from 1999 to 2009 (the read polygons) is close to-but not overlaid with - the location of cottonwood increase from vegetation mapping (the dark green area in the left and middle parts). In Fig. 9, the light green polygons represent the cottonwood occupied area from 1999 vegetation mapping; the dark green polygons represent the cottonwood area from 2007 vegetation mapping but not presented in 1999; the beige polygons represent the computational polygon with cottonwood in 1999; the red polygons represent the modeled cottonwood increase in 2007; the blue polygons represent the open water from 2007 vegetation mapping. The prediction error is partially attributed to the sparse original cross sections used in HEC-RAS. A high-resolution geometry is necessary to refine the model and create finer vegetation polygons.

The fine-scale spatial change occurring on the edge of cottonwood patches was not well captured by the model. For instance, the right top part of Figure 9a shows that the model did not predict the mapped cottonwood increase at RM 185.5, since there was no red polygon predicted around or at the location of the dark green areas. This is probably because the vegetation polygon is relatively large in contrast to the small spatial change that has taken place on the edge of vegetation patch. To predict this change, the cross section geometry must be thorough, and vegetation polygons need to be refined. 
The model tends to overestimate cottonwood establishment around oxbow lakes or isolated ponds. For example, in the upper part of Figure 9b, evident cottonwood increase was predicted around two oxbow lakes (the red polygons), while only a little cottonwood increase (small dark green polygons) was observed from vegetation mapping. The HEC-RAS model assumes that the water level of isolated water bodies is always consistent with the river stage of the main channel for a cross section. When the isolated water body is shallow, and evaporation or infiltration is high, water level decline in the isolated water body may be faster than river stage decline in the main channel, which may cause most isolated water bodies to be unfit for seedling survival. Nevertheless, the current HEC-RAS does not factor in these water level changes in oxbow lakes or isolated ponds, and results in too much cottonwood established around these water bodies.

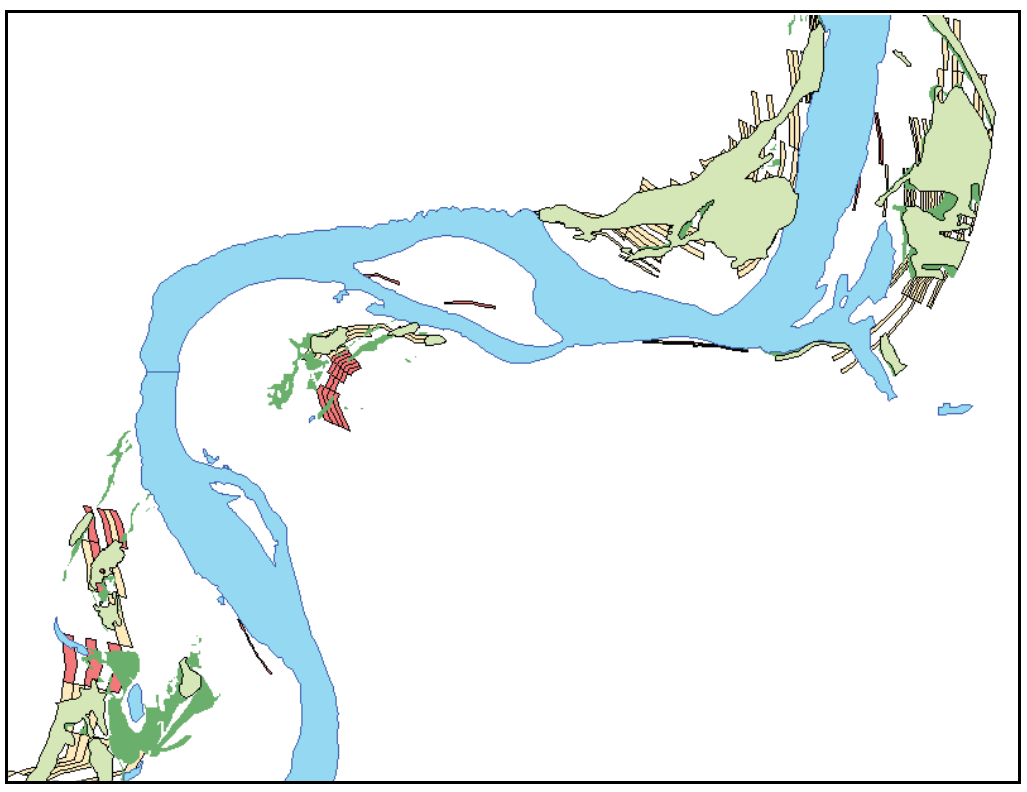

(a) RM 183.5-RM 186

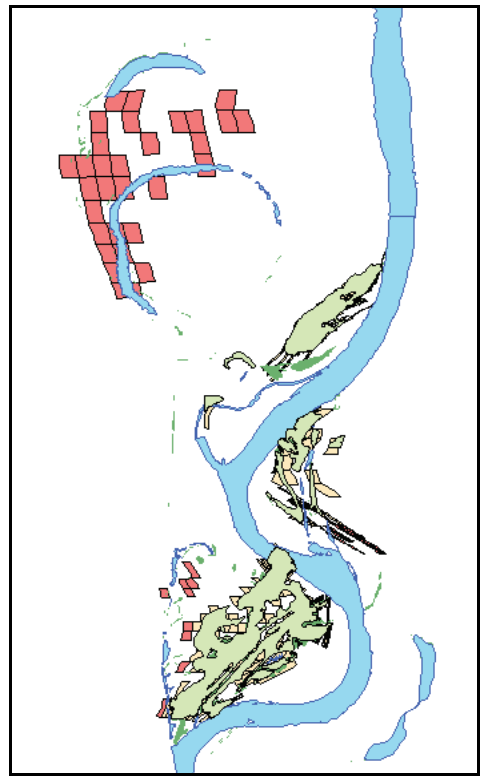

(b) RM 167-RM 163

Figure 9. Comparison of mapped and simulated spatial locations of cottonwood increase at two reaches.

Vegetation maps and model results discussed previously both indicate that cottonwood area increased by approximately $10 \%$ between 1999 and 2007, excluding the impact of restoration practice. It is worthwhile to further analyze the reason for the increase by examining the relationship between the cottonwood area and flow regime based on RVSM outputs. Figure 10 presents the simulated change in total area of living cottonwood as well as river stage hydrograph at RM 192.5 during the eight-year period. The figure shows that the increase of cottonwood area mainly took place in 2000 and 2004. In the rest years, the cottonwood area did not increase at the end of growing season. Previous studies (Rood et al. 1998; Stella 2005; Dixon et al. 2015) found that cottonwood seedling establishment depended on the floods exceeding a certain magnitude in spring prior to seed release. The floods created necessary bare and moist establishment sites at an elevation high enough to allow cottonwood to survive subsequent floods. The model reproduced this finding. The large spring floods in 2000, 2004, and 2006 enabled massive initial seedlings. In contrast, the small spring flood in 2001, 2002, and 2007 led to particularly limited initial seedling areas. The moderate flood in January 2003 occurred too early (mid-February to May) before seed release; thus, the flood did not trigger a massive seedling event. However, the number of seedlings that survive the first growing season is 
determined by the flow regime after germination (Mahoney and Rood 1998; Stella et al. 2010; Dixon et al. 2015). The simulated areas of dead cottonwood due to desiccation, drowning, scour, and competition are also shown in Figure 10. It reveals that desiccation was the primary cause of cottonwood seedling death. The sharp decline in river stage shortly after the start of seed germination season caused a large number of seedlings to die in 2000, 2003, 2004, 2005, and 2006. Among the three years with extensive initial seedlings, the abrupt river stage decline rate of about $15 \mathrm{~cm} / \mathrm{d}$ in late April and early May of 2006 was much greater than the rate of about $6 \mathrm{~cm} / \mathrm{d}$ in the same period of 2000 and 2004. This resulted in few seedlings surviving in 2006. The continuous river stage recession in the growing season from June to November imposed cumulative desiccation stress on seedlings and led to the gradual shrink of the cottonwood area in most years. In addition, the high flow that lasted longer than 15 days during the germination and growing seasons induced evident inundation death in 2001, 2002, 2004, and 2007.Therefore, favorable flow regimes in 2000 and 2004 that included large spring floods taking place not long before the start of germination and the gradual river stage recession during germination and growing seasons was predicted to contribute to the cottonwood area increase over the next eight years. This finding can help the environmental flow prescription for cottonwood restoration.

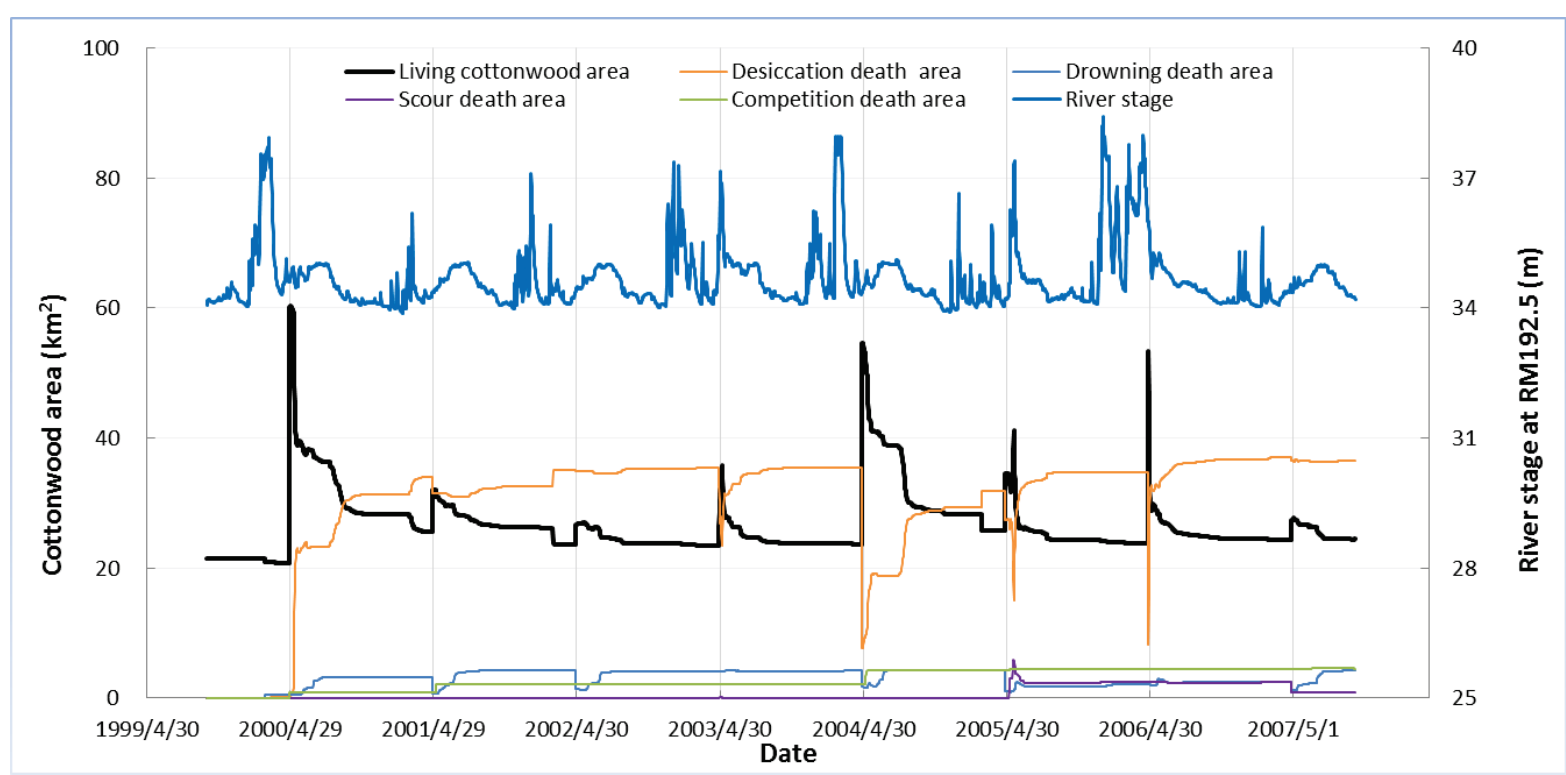

Figure 10. Total areas of living cottonwood and dead cottonwood due to desiccation, drowning, scour, and competition from the model.

Vegetation Sensitivity Analysis. As is stated in the above section, seedling elevation is sensitive to the height of the capillary fringe. The vegetation area is also affected by the height of the capillary fringe, since higher capillary fringe means more moist soil available for seed germination and seedling establishment. Figure 11 shows modeled vegetation areas of the five vegetation types at the end of simulation time when three different heights of capillary fringe varying between $0.164 \mathrm{ft}$ and $2 \mathrm{ft}$ were used. It was found that with increased capillary fringe, most vegetation types expand their areas, while only the grass area shrinks slightly. The grass area decreases, because the other vegetation types outcompete grass and occupy a small part of the space where grass grew previously. The sensitivity of capillary fringe height was also emphasized by the study of Elizabeth et al. (2011) on riparian cottonwood population dynamics. 
Therefore, it is suggested that when HEC-RAS-RVSM is used, the value of capillary fringe height should be carefully assigned based on field survey and model calibration, and the fringe's spatial variation should be taken into account if possible.

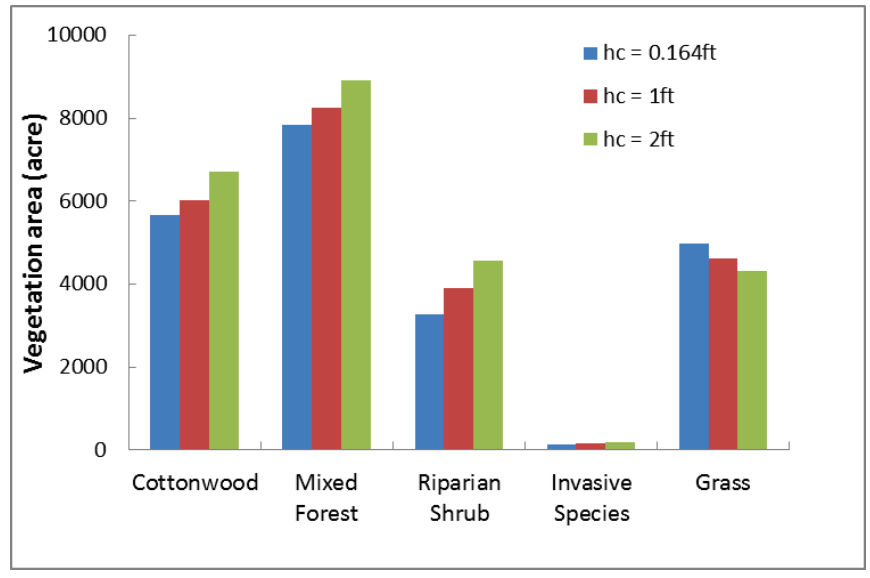

Figure 11. Simulated vegetation area change with height of capillary fringe $(\mathrm{hc})$ for each vegetation type.

Root growth rate is another sensitive parameter for the vegetation model calibration. The model assumes that desiccation stress will start when the root tip of riparian vegetation is above the capillary fringe, which is based on the point of many studies (Mahoney and Rood, 1998; Elizabeth et al. 2011). Since desiccation is the major cause of first-year seedling death, root growth rate plays a significant role in determining how many seedlings will survive the drought. Figure 12 illustrates that the predicted cottonwood area in 2007 at the end of simulation time gradually increases with increasing root growth rate from 1-10 mm/day. In the Sacramento River study, cottonwood root growth rate is set to $2 \mathrm{~mm} /$ day based on the outdoor experiment conducted at the University of California in Lafayette, California, from mid-July through late October 2002 (Stella 2005). The experiment observed that Cottonwood seedling had a growth rate ranging from 1.1-2.2 $\mathrm{mm} /$ day, lower than those reported elsewhere (Mahoney and Rood 1998; Roberts 2002; Meier 2008). Nevertheless, the predicted cottonwood seedling area and elevation roughly agree with the seedling observations in 2005 and 2006, for which root growth rate is equal to $2 \mathrm{~mm} /$ day (see Fig. 9 and 10 ). 


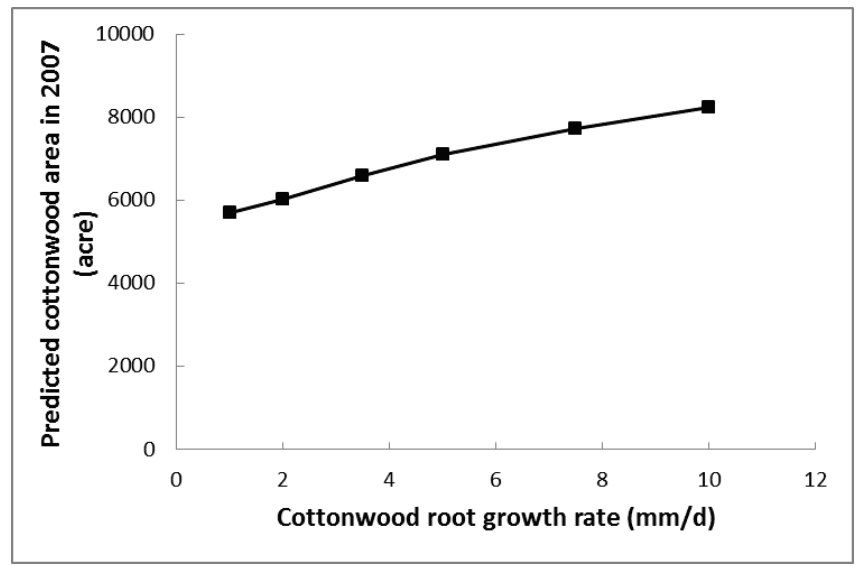

Figure 12. Relationship between cottonwood root growth rate and its area change between 1999 and 2007.

SUMMARY AND CONCLUSIONS: The HEC-RAS-RVSM was applied to the Sacramento River reach to demonstrate the model's capabilities for predicting dynamic riparian vegetation changes in response to hydraulic conditions. Five riparian vegetation types with cottonwood, mixed forest, riparian shrub, invasive species, and grass were simulated for the Sacramento River. Observed data with flow, river stage, groundwater level, cottonwood seedling density, and elevation collected at RM 192.5 and RM 183 in 2005 and 2006, and the 2007 vegetation mapping of the Sacramento River were used to calibrate and validate the model.

The HEC-RAS-RVSM model simulated the time of establishment; the model also predicted whether the cottonwoods survived and the elevation of recruitment. Model results were in agreement with observations that indicated the seedlings in the sandy soil would survive until the fall, but that no cottonwoods would survive in the gravelly soil. The model was able to reproduce the vegetation area increase of cottonwood, riparian shrub, invasive species, and grass as well as the area decrease in mixed forest over the eight-year period. By comparing cottonwood spatial change from vegetation mappings in 1999 and 2007, the HEC-RAS-RVSM was able to predict largescale cottonwood increase, but did not do well in simulating the fine-scale changes of cottonwood distribution around the edge of cottonwood patches. The model sensitivity analysis indicated that capillary fringe height and root growth rate are two critical parameters influencing the vegetation growth and survival in this study and needed to be carefully calibrated with observed data.

Overall, the HEC-RAS-RVSM model is capable of modeling the complex processes of vegetation response to geomorphic conditions and flow regime changes. The main limitations of RVSM are a heavy reliance on parameters to define the growth and removal of each simulated vegetation species. Prediction of dynamic vegetation variation is highly problematic and uncertain due to the wide array of quantitative and qualitative parameters involved in modeling vegetation lifecycle. A model calibration and a series of sensitivity runs are highly recommended in applying HEC-RAS-RVSM as a check on the parameter selection. For this reason, this tool is best used as a comparative predictor of scenarios instead of an absolute predictor of outcome for the evaluation of river systems and floodplain management actions. 
POINTS OF CONTACT: This technical note was prepared by Drs. Zhonglong Zhang and Billy Johnson of the U.S. Army Engineer Research and Development Center (ERDC), Dr. Junna Wang of the University of California at Davis, and Dr. Blair Greimann of the USBR. The study was conducted as an activity of the Ecosystem Management and Restoration Research Program (EMRRP).

For additional information, contact Drs. Zhonglong Zhang (zhonglong.zhang@erdc.dren.mil) and Billy Johnson (billy.e.johnson@erdc.dren.mil), or the EMRRP program manager, Dr. Trudy Estes (Trudy.J.Estes@usace.army.mil). This technical note should be cited as follows:

Zhang, Z., B. E. Johnson, J. Wang, and B. P. Greimann. 2019. Application and validation study of HEC-RAS-RVSM model to the Sacramento River. EMRRP Technical Notes Collection. ERDC/TN EMRRP-SR-88. Vicksburg, MS: U.S. Army Engineer Research and Development Center.

\section{REFERENCES}

Baptist, M., V. Babovic, J. U. Rodríguez, M. Keijzer, R. Uittenbogaard, A. Mynett, and A. Verwey. 2007. "On inducing equations for vegetation resistance. J. Hydraul. Res., 45(4): 435-450.

Borman, M. and L. L Larson. 2002. Cottonwood: Establishment, survival, and stand characteristics. EM 8800, Oregon State University Extension Service.

California Department of Water Resources. 2005. Cottonwood Seedling Monitoring During 2004 and 2005 along the Sacramento River, California. Draft Memorandum Report dated December 30, 2005. Northern District.

Cederborg, M. 2003. Hydrological requirements for seedling establishment of riparian cottonwoods (Populus Fremontii) along the Sacramento River, California. MS thesis, California State University, Chico, California.

Cheng, N. S. 2011. Representative roughness height of submerged vegetation. Water Resear. Res. $47(8)$ : W08517.

Dixon, M. D., C. J. Boever, V. L. Danzeisen, C. L. Merkord, E. C. Munes, M. L. Scott, W. C. Johnson, T. C. Cowman. 2015. Effects of a 'natural' flood event on theriparian ecosystem of a regulated large-river system: the 2011 flood on theMissouri River USA. Ecohydrology 8: 812-824.

Elizabeth, B. H., C. S. John, and K. F. Alexander. 2011. Global sensitivity analysis for complex ecological models: a case study of riparian cottonwood population dynamics. Ecological Applications 21(4): 1225-1240.

Fischer, R. A., and J. C. Fischenich. 2000. Design recommendations for riparian corridors and vegetated buffer strips. EMRRP Technical Notes Collection. ERDC TN-EMRRP-SR-24. Vicksburg, MS: U.S. Army Engineer Research and Development Center.

Fischenich, J. C. 2000. Resistance due to vegetation. ERDC TN-EMRRP-SR-07: Vicksburg, MS: US Army Engineer Research and Development Center.

Fotherby, L., J. V. Huang, and B. P. Greimann. 2012. Vegetation modeling with SRH-1DV: Predicting the interactions between flow, sediment, and riparian vegetation research and development. Technical Report No. SRH-2013-09. Denver, CO: U.S. Bureau of Reclamation Technical Service Center.

Freeman, G. E., W. J. Rahmeyer, and R. R. Copeland. 2000. "Determination of Resistance Due to Shrubs and Woody Vegetation." ERDC/CHL TR-00-25. Vicksburg, MS: U.S. Army Corps of Engineers Research and Development Center.

Greimann, B., and L. M. Fotherby. 2012. Calibrating a Riparian Vegetation Model forSacramento River Studies. World Environmental and Water ResourcesCongress, 1256-1268.

Harr, M. 1962. Groundwater and seepage. New York: McGraw-Hill. 
Horton, J. L., T. E. Kolb, and S. C. Hart. 2001. Physiological Response to Groundwater Depth Varies Among Species and With River Flow Regulation. Ecological Application 11(14):1046-1059.

Huthoff, F., D. Augustijn, and S. J. Hulscher. 2007. Analytical solution of the depth - averaged flow velocity in case of submerged rigid cylindrical vegetation. Water Resear. Res. 43(6): W06413.

Järvelä, J. 2004. Determination of flow resistance caused by non - submerged woody vegetation" Int. J. River Basin Manage. 2(1): 61-70.

Kouwen, N., and M. Fathi-Moghadam. 2000. Friction factors for coniferous trees along rivers. J. Hydraul. Eng. 126(10): 732-740.

Kouwen, N., and R. M. Li. 1980. Biomechanics of vegetative channel linings. J. Hydraul. Div. 106(HY6): 10851103.

Luhar, M., and H. M. Nepf. 2013. From the blade scale to the reach scale: A characterization of aquatic vegetative drag." Adv. Water Resour. 51: 305-316.

Mahoney, J. M., and S. B. Rood. 1998. Streamflow requirements for cottonwood seedling recruitment-an integrative model. Wetlands 18(4): 634-645.

Meier, C. I. 2008. Cottonwood Establishment in a Gravel-Bed River. University of Montana. Research theses and dissertation.

Meier, C. I., and F. R. Hauer. 2010. Strong effect of coarse surface layer on moisture within gravel bars: Results from an outdoor experiment. Water Resources Research 46: W05507.

Morgan, T. 2005. Hydrological and Physiological Factors Controlling Fremont Cottonwood Seedling Establishment Along the Sacramento River, California.Thesis, California State University, Chico, California.

Roberts M. D. et al. 2002. A Pilot Investigation of Cottonwood Recruitment on the Sacramento River. The Nature Conservancy, Sacramento River Project.

Rood, S. B., A. R. Kalischuk, and J. M. Mahoney. 1998. Initial cottonwood seedlingrecruitment following the flood of the century of the Oldman River Alberta.Can. Wetlands 18: 557-570.

Rood, S. B., Samuelson, G.M., Braatne, J.H., Gourley, C.R., Hughes, F.M., Mahoney,J.M., 2005. Managing river flows to restore floodplain forests. Front. Ecol.Environ. 3, 193-201.

Stella, J. C. 2005. A Field-Calibrated Model of Pioneer Riparian Tree Recruitment for the San Joaquin Basin, CA. University of California, Berkeley. Research theses and dissertation.

Stella, J.C., Battles, J.J., McBride, J.R., Orr, B.K., 2010. Riparian seedling mortalityfrom simulated water table recession, and the design of sustainable flowregimes on regulated rivers. Restor. Ecol. 18, 284-294.

Stromberg J. C., R. Tiller, and B. Richter. 1996. Effects of groundwater decline on riparian vegetation of semiarid regions: The San Pedro, Arizona. Ecological Application 6(1): 113-131.

Tal, M., Gran, K., Murray, A.B., Paola, C., Hicks, D.M., 2004. Riparian vegetation as a primary control on channel characteristics in multi-thread rivers. In: Riparian vegetation and fluvial geomorphology: hydraulic, hydrologic, and geotechnical interaction, S.J. Bennett and A. Simon (Eds.), American Geophysical Union Monograph 4358.

USACE. 2002. Sacramento and San Joaquin River Basins, California, Comprehensive Study, Technical Studies Documentation. Sacramento District: U.S. Army Corp of Engineers. December 2002.

USBR. 2009. Calibration of Numerical Models for the Simulation of Sediment Transport, River Migration, and Vegetation Growth on the Sacramento River, California. Technical Report No. SRH-2009-27. Denver, Colorado: Bureau of Reclamation, Technical Service Center.

Viers, J. H., and R. A. Hutchinson. 2008a. Rapid Assessment Mapping in the Sacramento River Ecological Management Zone - Colusa to Red Bluff, Sacramento River Monitoring and Assessment Program. Geographical Information Center, California State University, Chico. 
Viers, J. H., and R. A. Hutchinson. 2008b. Sacramento River Vegetation Map Cross-Walk Comparison and Calibration Between Maps Created in 1999 and 2007. A Technical Report to the CAL-FED Ecosystem Restoration Program. University of California, Davis.

Whittaker, P., C. A. Wilson, and J. Aberle. 2015. "An improved Cauchy number approach for predicting the drag and reconfiguration of flexible vegetation." Adv. Water Resour., 83, 28-35.

Zhang, Z., B. E. Johnson, and B. P. Greimann. 2018. HEC-RAS-RVSM (riparian vegetation simulation module). EMRRP Technical Notes Collection. ERDC TN-EMRRP-SR-87. Vicksburg, MS: U.S. Army Engineer Research and Development Center.

Zimmerman, Robert C. 1969. Plant Ecology of an Arid Basin Tres Alamos-Redington Area Southeastern Arizona, Geological Survey Professional Paper 485-D, U.S. Geological Survey, Washington D.C., 52 p.

NOTE: The contents of this technical note are not to be used for advertising, publication, or promotional purposes. Citation of trade names does not constitute an official endorsement or approval of the use of such products. 